\title{
UNA PROPUESTA DE ANÁLISIS DE TRAYECTORIAS DE JUSTICIA TRANSICIONAL
}

\author{
Martha Liliana Gutiérrez Salazar ${ }^{(a)}$
}

\author{
A PROPOSAL FOR AN ANALYSIS OF THE TRAJECTORIES \\ OF TRANSITIONAL JUSTICE
}

UMA PROPOSTA DE ANÁLISE DE TRAJETÓRIAS DA JUSTIÇA DE TRANSIÇÃO

Fecha de recepción: 30 de septiembre del 2017

Fecha de aprobación: 9 de enero del 2018

Sugerencia de citación:

Gutiérrez Salazar, M. L. (2018). Una propuesta de análisis de trayectorias de justicia transicional. Razón Crítica, 4, 23-44, doi: http://dx.doi.org/10.21789/25007807.1281

* Este artículo hace parte del proyecto "Justicia Transicional en América Latina: Trayectorias Comparadas", financiado por la Universidad de Bogotá Jorge Tadeo Lozano mediante su convocatoria permanente de investigación, identificado con código 814-CP-17, que es desarrollo de una propuesta previa elaborada durante mi formación doctoral.

(a) Doctora en Procesos Políticos Contemporáneos de la Universidad de Salamanca, Máster en Estudios Latinoamericanos de la Universidad de Salamanca y abogada de la Universidad de Caldas. Profesora de tiempo completo de la Facultad de Ciencias Sociales de la Universidad de Bogotá Jorge Tadeo Lozano, Bogotá - Colombia https://orcid.org/0000-0002-5198-2273 marthal.gutierrezs@utadeo.edu.co 


\section{R E S U M E N}

Pasado un tiempo desde la tercera ola de democratización, los estudiosos de la justicia transicional se plantean nuevas preguntas y, además de indagar por la conveniencia de implantar determinados mecanismos de rendición de cuentas, se ha abordado el estudio de las trayectorias de dichos mecanismos y su evolución a través del tiempo. Lo que evidencian los estudios sobre América Latina es un paso desde patrones de impunidad a mayor rendición de cuentas, reflejada en el incremento de juicios y la invalidación de amnistías, pero no se trata de una tendencia uniforme, por lo que resulta necesario estudiar el tema de forma comprehensiva, analizando también lo que ha pasado en materia de verdad y reparación. Algunos esfuerzos académicos han permitido avanzar en ello, pero es necesaria la construcción de un marco de análisis que facilite la comparación de los mecanismos y sus trayectorias. El presente trabajo se dirige a esta construcción mediante una propuesta que permita diferenciar diversos grados en los que se garantizan los derechos de las víctimas, en un continuo que va desde la impunidad hacia la rendición de cuentas.

PALABRAS CLAVE: justicia transicional, trayectorias, impunidad, rendición de cuentas. 


\section{A B S T R A C T}

Sometime after the third wave of democratization, scholars of Transitional Justice are asking new questions. Besides inquiring on the convenience of implementing specific mechanisms of accountability, a study has been carried out on the trajectories of such mechanisms and their evolution through time. What these studies evidence in regards to Latin America is a step from impunity patterns to a higher level of accountability, reflected on the increase of trials and the invalidation of amnesties, a tendency that is not, however, uniform, which is why it is necessary to study the matter in a comprehensive way, analyzing what has happened in issues of truth and reparations. Academic efforts have allowed this matter to move forward, but the construction of a framework that facilitates the comparison of such mechanisms and their trajectories is necessary. The present paper is directed towards this goal through a proposal that allows a distinction between the diverse degrees in which the victim's rights are guaranteed, in a continuum that goes from impunity to accountability.

\section{KEY WORDS: transitional justice, trajectories, impunity, accountability.}

\section{R E S U M O}

Depois da terceira onda de democratização, os estudiosos da justiça de transição fazem-se novas perguntas e, além de indagar sobre a conveniência de estabelecer determinados mecanismos de prestação de contas, aborda-se o estudo das trajetórias desses mecanismos bem como da sua evolução ao longo do tempo. Os estudos sobre a América Latina evidenciam que foi dado um passo de padrões de impunidade a uma prestação de contas cada vez maior, refletida no aumento de julgamentos e na invalidação de anistias; contudo, não se trata de uma tendência uniforme, portanto é necessário estudar o assunto de forma abrangente e analisar, também, o que tem ocorrido quanto a temas de verdade e reparação. Certos esforços acadêmicos têm permitido avançar na matéria, mas é preciso construir um quadro de análise que facilite a comparação dos mecanismos e das suas trajetórias. Este trabalho foca-se nessa construção por meio de uma proposta que permite diferenciar diversos graus em que são garantidos os direitos das vítimas, desde a impunidade até a prestação de contas.

PALAVRAS-CHAVE: justiça de transição, trajetórias, impunidade, prestação de contas. 


\section{N T R O D U C C I Ó N}

Una de las preguntas de la literatura contemporánea sobre justicia transicional es ¿cuál es la trayectoria de los mecanismos adoptados para lidiar con los crímenes del pasado? Dicha pregunta ha sido abordada por estudios cuantitativos (Olsen, Payne, y Reiter, 2010), estudios cualitativos centrados en países y, más recientemente, en un estudio que abarca nueve países de América Latina (Skaar, García-Godos, y Collins, 2016). No obstante, para propiciar nuevas comparaciones sistemáticas, el presente trabajo propone un marco de análisis que permita diferenciar diversos grados en los que se garantizan los derechos de las víctimas, en un continuo que va desde la impunidad hacia la rendición de cuentas.

La base del marco analítico que se propone está conformada por los derechos a la verdad, la justicia y la reparación. Para indagar por su efectividad, se plantea revisar los mecanismos de justicia transicional que conducen a su garantía, partiendo del conjunto de principios actualizado para la protección y la promoción de los derechos humanos mediante la lucha contra la impunidad (principios para la lucha contra la impunidad) (Comisión Colombiana de Juristas, 2007), así como los principios sobre el derecho de las víctimas a interponer recursos y obtener reparaciones (principios para la reparación) (Comisión Colombiana de Juristas, 2007).

La aplicación en periodos sucesivos de los criterios de análisis que se proponen permitirá conocer las trayectorias de los mecanismos de justicia transicional, entendidas como los cambios que a lo largo del tiempo se dan en las garantías de verdad, justicia y reparación. Así mismo, a través de la aplicación de los diversos niveles de marco analítico se podrán comparar de forma independiente trayectorias de estas garantías.

Ello permitirá diferenciar aquellos países donde no se han adoptado medidas de justicia transicional de otros donde se ha puesto el acento en algún mecanismo específico, para luego dar 
lugar a su profundización o a la aplicación de otros mecanismos, así como evidenciar esfuerzos más recientes que buscan mayor integralidad y complementariedad de las garantías a la verdad, la justicia y la reparación.

\section{Estudios sobre justicia transicional en América Latina}

Hoy en día, la justicia transicional se entiende como el conjunto de medidas que se adoptan para hacer frente a abusos masivos de los derechos humanos (De Greiff, 2011) y abarca diversos mecanismos encaminados a que los responsables de estos abusos rindan cuentas de sus actos, además de contribuir a la reconciliación (ONU, 2004). Dichos mecanismos son, por ejemplo, las comisiones de la verdad, los juicios, las purgas y las reparaciones. ${ }^{1}$

En América Latina comenzó a hablarse en términos de justicia transicional a partir de mediados de los años 90 con la compilación de Krtiz (1995). No obstante, desde antes, autores como O’Donnell y Schmitter (1986) venían reflexionando sobre transiciones y modos de evitar retrocesos autoritarios, es decir, de evitar que los militares que habían dejado el poder se sintieran tentados a recuperarlo ante la amenaza de ser perseguidos por sus actos.

Desde aquellas primeras discusiones se ha avanzado en la construcción de estudios empíricos que evidencian que las medidas de justicia transicional se han extendido a lo largo del tiempo después de las transiciones, y que los acuerdos inicialmente pactados se han modificado con el transcurso de los años, encontrando que al inicial establecimiento de comisiones de la verdad han sobrevenido la realización de juicios, a pesar incluso del otorgamiento de amnistías (Sikkink y Booth Walling 2007), y, más tarde, medidas de justicia restaurativa (Olsen et ál., 2010).

La implementación de mecanismos de justicia transicional en la región ha sido entonces variada y diversa, y se refleja en los avances que ha mostrado la literatura sobre el tema, donde han primado trabajos que se concentran en un mecanismo, frente a aquellos que

1 Para una revisión bibliográfica más amplia sobre justicia transicional, véase Gutiérrez, 2015a. 
tratan de observar la interacción entre los diferentes mecanismos tendientes a lidiar con los abusos del pasado. También, priman los estudios por país frente a los comparados, campo en el que cabe resaltar el valioso aporte de Skaar et ál. (2016).

En cuanto estudios particulares sobre mecanismos, debemos referir los trabajos de Popkin y Roth-Arriaza (1995), Popkin y Bhuta (1999) y Hayner (2001 y 2011), quienes analizan comisiones de la verdad en Argentina, Chile, Ecuador, El Salvador, Guatemala, Haití, Honduras, Paraguay y Perú. En materia de juicios y amnistías, encontramos los trabajos de Burt (2009); Collins (2009); Laplante (2009); Payne, Abrão y Torelly (2011); Skaar (2011); Abrão y Torelly (2012); Burt (2012); Martínez, Gutiérrez y Rincón (2012); Smulovitz (2012); Collins, Balardini y Burt (2013); y Gutiérrez (2015b), sobre Argentina, Chile, El Salvador, Guatemala, Perú y Uruguay. Sobre reparaciones, podemos citar a Correa (2011) y Abrão y Torelly (2011), quienes estudian los programas implementados en Argentina, Brasil Chile y Perú.

Hay, además, otros estudios ya no centrados en mecanismos de justicia transicional, sino en otros temas específicos. Uno de dichos temas, con un importante desarrollo, es el referido al Sistema Interamericano de Derechos Humanos y su relación con la justicia transicional en la región o en países específicos, donde destacan los estudios de Salazar y Antkowiak (2007); Sandoval (2008); Huneeus (2011); Dutrénit (2012); y Bernardi (2013; 2015a; 2015b).

La mayor parte de los estudios citados analizan aspectos no siempre coincidentes y comparables, más aún cuando se concentran muchas veces en países e incluso en unidades de análisis más pequeñas, como juicios particulares a algún exrepresor. Es por ello que, a pesar del considerable número de académicos dedicados al estudio de la justicia transicional en América Latina, todavía es necesario desarrollar un marco analítico que permita la comparación empírica minuciosa de los diferentes mecanismos de justicia transicional, y que, aplicado a lo largo del tiempo, contribuya a establecer sus trayectorias, permitiendo además la comparación sistemática entre países, a lo que se dirige la segunda sección de este trabajo.

Vale la pena antes detenerse en el texto de Skaar et ál. (2016), no solo por su pertenencia, al tratarse de un análisis comparado para América Latina, sino porque en él se busca analizar trayectorias 
de justicia transicional en nueve países de la región, resultando necesario resaltar puntos de coincidencia y divergencia entre el marco de análisis allí propuesto y el que se presenta más adelante.

El propósito común de ambos marcos analíticos es guiar descripciones profundas sobre trayectorias de justicia transicional, desde la impunidad hacia la rendición de cuentas, que sirvan de matriz para estudios empíricos comparativos. No obstante, las divergencias son varias.

Para empezar, la definición de rendición de cuentas que propone el libro en cuestión se refiere al reconocimiento explícito por parte del Estado de que graves violaciones a los derechos humanos han ocurrido en su territorio y de que dicho Estado se ha visto envuelto en su ocurrencia o es responsable de ellas (Skaar et ál., 2016, p. 4). Entre tanto, como se verá más adelante, en la presente propuesta la rendición de cuentas se entiende como lo contrario a la definición de impunidad consagrada en los principios de la ONU (2005), que se presenta por la no garantía de los derechos a la verdad, la justicia y la reparación.

Por otro lado, aquí se opta por un análisis con mayor profundidad de cada uno de los mecanismos de justicia transicional y, en consecuencia, por una guía más detallada de análisis que garantice que al comparar un país con otro, o un periodo con otro, se esté hablando de lo mismo. Así, por ejemplo, como lo reconocen las autoras del volumen aludido, al analizar las diversas comisiones de la verdad, se encuentran importantes diferencias entre ellas (Skaar et ál., 2016, p. 29), diferencias que se pretenden resaltar de forma sistemática con la presente propuesta.

No se incluyen aquí algunos aspectos que sí tienen en cuenta Skaar et ál., como la implementación y cumplimiento de las recomendaciones de las comisiones de la verdad. Tampoco se plantea en el presente trabajo estudiar las amnistías de forma separada a los juicios por considerarlas condicionantes de los mismos. Finalmente, el libro de Skaar et ál. busca tener un alcance explicativo que sobrepasa el propósito del marco analítico propuesto aquí, que por el contrario persigue alcanzar descripciones más minuciosas de los mecanismos de justicia transicional y sus trayectorias antes de pasar a las posibles explicaciones.

Mientras la premisa básica de Skaar et ál. (2016, p. 38) es que la presencia de mecanismos de justicia transicional en un país 
importa para la rendición de cuentas, aquí se entiende que no solo es necesario profundizar aún más sobre el contenido y alcance de tales mecanismos, sino que es necesario hacerlo sobre criterios más estrictos que beneficien la comparación, ya sea de países o de mecanismos individualmente considerados. ${ }^{2}$

\section{Propuesta de marco analítico}

Los principios contra la impunidad de la ONU la definen como ausencia de responsabilidad y señalan que la lucha contra esta incluye, además de la obligación de perseguir los autores de las violaciones, la de garantizar verdad y reparación (Comisión Colombiana de Juristas, 2017). La impunidad puede ser entendida entonces como la falta de garantía sobre el derecho a conocer la verdad, la inexistencia de responsabilidad penal de los presuntos autores de violaciones o crímenes del pasado y la ausencia de garantías para obtener reparaciones. La rendición de cuentas por los crímenes del pasado sería lo opuesto.

De las obligaciones generales de los Estados en la lucha contra la impunidad, se pueden extraer una serie de deberes que se utilizan como base para la construcción del marco analítico que se propone. La realización completa e ideal de las previsiones contenidas en los principios es tomada como punto final de una recta que va desde la impunidad hasta la garantía de los derechos de las víctimas de crímenes del pasado.

Por trayectoria de los mecanismos de justicia transicional, se entienden las variaciones que a lo largo del tiempo se dan en las garantías de verdad, justicia y reparación. Esto es, los diferentes grados en los que a través del tiempo se garantizan estos derechos, como ocurre en aquellos casos donde los juicios han tenido mayor presencia en determinados momentos, viéndose interrumpidos por periodos para luego resurgir con fuerza -como ocurrió en Argentina- o en aquellos casos donde se implementaron

2 Para analizar la calidad de los mecanismos de justicia transicional, Skaar et ál. (2016, p. 42) plantean la formulación de un cuestionario a los autores de los diversos capítulos, que en algunos aspectos coincide con los criterios emanados de los principios contra la impunidad y sobre reparaciones de la ONU (2005), pero que en otros aspectos no lo hace, y que, además, no guía la construcción de los estudios de caso, como se espera lo haga la propuesta aquí planteada. 
comisiones de la verdad muchos años después de las transiciones -como en Brasil-.

\section{A. Verdad}

Se entiende el conocimiento de la historia como un derecho de naturaleza colectiva que hace parte del patrimonio de los pueblos. A los Estados corresponde, además, el deber de recordar. Esto se cumple mediante la preservación de archivos y pruebas, la facilitación del conocimiento de las violaciones y evitando que surjan tesis revisionistas o negacionistas. ${ }^{3}$

El derecho a la verdad puede ser garantizado mediante mecanismos como juicios, comisiones de la verdad y aseguramiento de las posibilidades de reconstrucción de los hechos: impedir la desaparición de pruebas, garantizar la preservación de archivos sobre las violaciones y la posibilidad de consultarlos. Así mismo, mediante otros mecanismos judiciales o administrativos como los habeas corpus y las exhumaciones (ACNUDH, 2006).

Para estudiar empíricamente el derecho a la verdad, se propone analizar: (i) las comisiones de la verdad, específicamente, la procedencia y el alcance de la verdad que reflejan, el reconocimiento externo de la verdad que documentan y la apropiación local de dicha verdad; (ii) la conservación de archivos, y (iii) los esfuerzos en materia de exhumaciones y búsqueda de desaparecidos.

\section{i. Comisiones de la verdad}

Entre los mecanismos más destacados para hacer efectivo el derecho a la verdad se encuentran las comisiones de la verdad que, en un principio, ante las dificultades que se pensaba implicarían los juicios, se entendieron como medio de catarsis social, forma de reproche y censura (Zalaquett, 1992).

3 El derecho a la verdad fue objeto de la Resolución 2005/66 de la Comisión de Derechos Humanos de las Naciones Unidas, que dispuso la elaboración de un estudio presentado en 2006 por el Alto Comisionado de las Naciones Unidas para los Derechos Humanos (ACNUDH). De acuerdo con la ONU, este derecho "ha alcanzado el estatus de norma de derecho internacional consuetudinario” (Méndez, 2011, p. 202). El estudio del ACNUDH (2006) señala que "el derecho a la verdad entraña tener un conocimiento pleno y completo de los actos que se produjeron, las personas que participaron en ellos y las circunstancias específicas, en particular de las violaciones perpetradas y su motivación." (ACNUDH, 2006, p. 209). 
El principio seis para la lucha contra la impunidad señala la relevancia de que las comisiones garanticen "el reconocimiento de partes de verdad que anteriormente se negaban" (Comisión Colombiana de Juristas, 2007, p. 40), ${ }^{4}$ mientras el principio siete resalta la importancia de la independencia, imparcialidad y competencia de las comisiones. Finalmente, el principio 13 señala que los informes de las comisiones deben hacerse públicos y ser difundidos con amplitud, en la medida de lo posible. Van Zyl (2011) aboga por la necesidad de la apropiación local y control nacional de las comisiones y Olsen et ál. (2010) señalan que para que una comisión de la verdad sea exitosa, debe reunir tres condiciones: que la verdad sea completa, oficialmente proclamada y públicamente expuesta. ${ }^{5}$

Los anteriores aspectos -procedencia de la verdad, alcance, reconocimiento de la verdad documentada y apropiación local-son la base para el análisis de los diversos grados en que se garantiza la rendición de cuentas en materia de comisiones de la verdad.

Cuando se habla de procedencia, se trata de examinar la solemnidad o formalidad con la cual fue establecido el organismo del cual procede la verdad, así como la rigurosidad y publicidad de los procedimientos que ha seguido para el conocimiento de los hechos.

Si la Comisión ha sido establecida de forma solemne, con transparencia en su conformación y financiación, asegurando la imparcialidad de sus miembros mediante la aplicación de procedimientos rigurosos, se entenderá que asegura mayor rendición de cuentas que cuando no se garantiza ninguno de estos aspectos o se garantizan solo algunos de ellos. ${ }^{6}$

4 Sobre ello señala Van Zyl (2011, p. 51): "Es importante no solo hacer saber ampliamente que han ocurrido violaciones de los derechos humanos, sino también que los Gobiernos, los ciudadanos y los perpetradores reconozcan la injusticia de tales abusos”.

5 En relación con el mandato, se ha dicho que "las comisiones de la verdad no deben ser sustitutos para la justicia ni acuerdos convenientes entre la responsabilidad y la impunidad" (Van Zyl, 2011, p. 67). En este sentido, el principio ocho contra la impunidad señala que "la finalidad de las comisiones no consistirá en reemplazar la justicia, tanto civil o administrativa como penal” (Comisión Colombiana de Juristas, 2007, p. 40).

6 Algunos países han establecido comisiones de la verdad que han sido ampliamente cuestionadas por ser consideradas parcializadas, como ocurrió en Ecuador en 2007, cuando Rafael Correa quiso que se investigaran violaciones de derechos humanos ocurridas en un gobierno pasado y para hacerlo integró el organismo de seguidores declarados de Alianza País. Algo opuesto a lo que se espera ocurra en Colombia, donde se 
En materia de alcance, debe considerarse la necesidad de que la comisión proporcione una verdad que vaya más allá de casos paradigmáticos o ilustrativos y permita conocer los hechos y comprender cómo y por qué sucedieron. Si el informe identifica las atrocidades que se cometieron, así como a las personas o grupos responsables -sin necesidad de que se aporten nombres o las circunstancias en que ocurrieron los hechos-, se entenderá que garantiza en mayor medida la rendición de cuentas que aquellos informes que se centran en casos paradigmáticos o patrones generales de violencia, que dejan víctimas invisibilizadas. ${ }^{7}$

Por otro lado, más allá de la procedencia del organismo encargado de rendir un informe, y del alcance de dicho informe, es necesario examinar cómo es recibido este resultado por los actores involucrados en las atrocidades del pasado. Para atender las diferencias entre conocimiento y reconocimiento de la verdad, junto con la necesidad de que el reconocimiento provenga del Estado en su conjunto, si la verdad contenida en el informe es pública y oficialmente reconocida por el gobierno y los demás poderes públicos (legislativo y judicial), se entiende que hay mayor rendición de cuentas que cuando alguno de dichos poderes o sus funcionarios y representantes desconocen el contenido del informe o lo tachan de falso o parcializado. Este es un punto en el que los resultados del análisis pueden variar si se hace una mirada longitudinal, debido al surgimiento de tesis revisionistas o negacionistas, o a la emisión de condenas judiciales que reconozcan responsabilidades que antes se negaban, lo que equivaldría al reconocimiento oficial de la verdad por parte de uno de los órganos del Estado. ${ }^{8}$

\footnotetext{
ha establecido una instancia independiente de selección de miembros de la Comisión de la Verdad, a través de un proceso abierto a la opinión pública.

7 Un ejemplo clásico de una comisión de la verdad que produjo un informe con un amplio alcance es Guatemala, donde además la sociedad civil aportó un trabajo previo de investigación y recolección de información, mientras en El Salvador, con una comisión con mayores limitaciones de todo tipo, el informe se centró en casos ilustrativos, lo que, sin desconocer su importancia, dejó fuera de él a una gran cantidad de víctimas, que tampoco han visto garantizados sus derechos por otros medios.

8 Aquí de nuevo son ilustrativos los casos de El Salvador y Guatemala. En el primer país, el informe de la comisión de la verdad produjo un rechazo inmediato por parte del establecimiento, lo que se ha modificado levemente en algunos momentos de la historia reciente, específicamente durante el gobierno de Mauricio Funes. Mientras en Guatemala, el juicio por genocidio contra el exdictador Efraín Ríos Montt implicó un aumento de tesis revisionistas, que niegan la ocurrencia del genocidio y, con ello, la validez y contenido del informe.
} 
Finalmente, es necesario que la comisión de la verdad esté revestida de apropiación y control nacional, es decir, que no haya sido impuesta desde afuera o, que si lo ha sido, consiga integrarse como parte de un proyecto local, de forma que no se reconozcan sus resultados como una verdad de extranjeros y, por el contrario, sirva de catarsis en el ámbito local y de reproche a los perpetradores. Para ello habrá que examinar si al establecimiento de la comisión le preceden consultas locales sobre aspectos como la conveniencia de su establecimiento, la elección de sus miembros, entre otros, y sí después de producido el informe, su contenido es ampliamente difundido y se asegura el conocimiento del pasado por la población en general. ${ }^{9}$

\section{ii. Archivos}

Los principios contra la impunidad señalan la necesidad de preservar archivos tanto para garantizar el derecho a saber, como para que las víctimas y acusados tengan acceso a los mismos (tomando las medidas necesarias para impedir que sean alterados). Ello sin perjuicio de la confidencialidad de que gozan los testigos y víctimas que colaboran con las comisiones de investigación para esclarecer violaciones del pasado.

Así las cosas, para garantizar el derecho a la verdad es necesario proteger las fuentes de información necesarias para el esclarecimiento de la verdad, así como asegurar posibilidades suficientes de acceder a ellas. Para analizar la efectividad con que se asegura tal derecho, deben considerarse entonces las garantías que se ofrecen para salvaguardar archivos militares, judiciales, estatales y de cualquier otra índole que den luces sobre las violaciones, para consultarlos y para impedir la desaparición de pruebas. ${ }^{10}$

\section{iii. Exhumaciones y búsquedas}

En los casos de desapariciones forzadas "la familia de la víctima directa tiene el derecho imprescriptible a ser informada de la

\footnotetext{
$9 \quad$ Se entiende que la inclusión de los resultados del informe (o temas relativos al mismo) en textos escolares asegura el conocimiento general de la verdad producida por la comisión, siempre y cuando el sentido de los textos se atenga al sentido del informe. 10 Casi diez años después de la transición en Guatemala, en 2005 fue descubierto, accidentalmente, el archivo de la antigua policía nacional con información relevante para causas penales y el esclarecimiento de la verdad por los crímenes del pasado, especialmente sobre un sinnúmero de desapariciones.
} 
suerte y/o el paradero de la persona desaparecida y, en caso de fallecimiento, se le debe restituir el cuerpo en cuanto se identifique" (Comisión Colombiana de Juristas, 2007, p. 51): para garantizar el derecho a la verdad, es necesario también garantizar la búsqueda de pruebas que conduzcan al esclarecimiento de los hechos y la realización de procedimientos como las exhumaciones.

Considerando los esfuerzos para conocer la suerte y paradero de las víctimas desaparecidas, su búsqueda y la realización de exhumaciones con identificación y restitución de restos, se debe diferenciar entre aquellos escenarios donde dichos esfuerzos no cuentan con apoyo oficial -o que tendiéndolo, disponen de recursos limitados-, de acuerdo al contexto, de aquellos otros en los que el Estado lidera la realización de exhumaciones, con identificación y restitución de los restos a los familiares de la víctima, y también de aquellos casos donde simplemente no puede hablarse de una verdadera voluntad encaminada a realizar búsquedas y exhumaciones. ${ }^{11}$

\section{B. Justicia}

El derecho a la justicia está ampliamente reconocido por el Derecho Internacional, empezando por los artículos 8 a 11 de la Declaración Universal de los Derechos Humanos de 1948. Considerados como el más emblemático de los mecanismos de justicia transicional, los juicios "representan un esfuerzo para llevar ante la justicia a quienes han cometido violaciones a los derechos humanos" (Olsen et ál., 2010, p. 32).

El principio 19 contra la impunidad prevé que "los Estados emprenderán investigaciones rápidas, minuciosas, independientes e imparciales" de las violaciones, especialmente en el ámbito penal. Así mismo, advierte que, aunque las investigaciones deberían iniciarse por iniciativa de los Estados “deberán adoptarse las normas procesales complementarias para que las propias víctimas, sus familiares o herederos puedan tomar esa iniciativa" (Comisión Colombiana de Juristas, 2007, p. 45).

11 En este punto el trabajo de organizaciones no gubernamentales, como el Equipo Argentino de Antropología Forense, ha sido fundamental. En estos casos, habrá que analizar el respaldo y apoyo que este tipo de organizaciones reciben desde la institucionalidad, tanto en su propio país como en otros de la región. 
A pesar del reconocimiento expreso de este derecho, en la literatura se encuentran diferentes aproximaciones que van desde aquellos que señalan que perseguir las atrocidades del pasado es un imperativo moral, ético y legal, a la luz de diversas normas del derecho internacional (McAdams, 1997; Méndez, 2011), hasta la de quienes sostienen que "la paz no puede pensarse ni practicarse sin la justicia” (Valencia Villa, 2007, p. 164) y que el derecho a la justicia solo deberá restringirse previo juicio de proporcionalidad (Uprimny y Lasso, 2004). ${ }^{12}$

Para estudiar empíricamente el derecho a la justicia, se propone indagar por la existencia de investigaciones penales tendientes a que se establezca la responsabilidad individual de los perpetradores en el ámbito doméstico. Puede también indagarse por las cifras de condenados, quantum de las penas y número de condenados privados de libertad, condenados fugados y condenados gozando de beneficios, pero no como reflejo de la garantía del derecho a la justicia, puesto que lo importante sería que lo juicios se realicen de manera razonablemente rápida, minuciosa e imparcial, y no que lleven siempre a una condena.

Las investigaciones deben tardar un tiempo razonable, pero no tanto que impliquen denegación de justicia por inactividad del Estado, por lo que al analizar el tiempo que duran las investigaciones y juicios, se debe otorgar un margen amplio a los aparatos judiciales nacionales para el desarrollo de cada una de las etapas procesales. ${ }^{13}$

Es necesario, además, que las investigaciones se adelanten con diligencia y cuidado, recogiendo el material probatorio que corresponda, persiguiendo los crímenes graves sin que algunos de los perpetradores se vean beneficiados con fueros velados que los libren de responsabilidad. Dadas las dificultades para criminalizar la totalidad de las violaciones, resulta entendible que los Estados prioricen, pero dicha estrategia no debe estar encaminada a dejar por fuera a los máximos responsables. Se deberá examinar entonces

\footnotetext{
12 Para una justificación detallada del deber de adelantar juicios, véase Méndez (2011).

13 Sin llegar al extremo de contabilizar, como lo hacen algunos estudios de tipo cuantitativo, las investigaciones que se eternizan sin ningún avance sustantivo. Se debe además diferenciar entre aquellos países que adelantan megacausas o investigaciones con un número elevado de sindicados, como ocurre en Argentina, de aquellos países donde por cada sindicado se abre una investigación, como ocurre en Chile.
} 
si las investigaciones se dirigen hacia los máximos responsables de los crímenes más graves, o si se concentran en rangos medios y bajos.

Para analizar este punto, empíricamente es necesario tener en cuenta el perfil de los investigados y el cumplimiento del deber de investigar -atendiendo al número de preclusiones, sobreseimientos o absoluciones por falta de recaudo probatorio-; así como la imparcialidad de los funcionarios, que puede ser cuestionada, por parte de organismos nacionales e internacionales y denuncias de prensa, en casos abiertamente contrarios a las normas internas o internacionales.

\section{Reparación}

El principio 31 contra la impunidad señala que "toda violación de un derecho humano da lugar a un derecho de la víctima o sus derechohabientes a obtener reparación" (Comisión Colombiana de Juristas, 2007, p. 50). Ello puede hacerse tanto por la vía judicial, como mediante programas establecidos por el legislativo o mediante medidas administrativas. Los principios sobre reparaciones señalan que corresponde a los Estados "establecer programas nacionales de reparación y otra asistencia a las víctimas cuando el responsable de los daños sufridos no pueda o no quiera cumplir sus obligaciones" (Comisión Colombiana de Juristas, 2007, p. 224), así como ejecutar las sentencias nacionales y extranjeras que le impongan reparaciones con arreglo a sus obligaciones. Para estudiar empíricamente el derecho a la reparación, se propone entonces examinar los programas de reparaciones masivas, las reparaciones simbólicas y las reparaciones judiciales.

\section{i. Programas de reparaciones materiales masivas}

De Greiff (2011) diferencia dos contextos en el uso del término "reparaciones": uno jurídico, aplicable principalmente en el marco del derecho internacional, y otro referido a programas de cobertura masiva, donde el mencionado término tendría un sentido restringido dada la dificultad práctica para que un programa de reparaciones cumpla con los estándares del derecho internacional. Esta diferenciación lo lleva a distinguir entre las exigencias de justicia en casos aislados y en casos masivos.

El autor señala que hay circunstancias en las que la reparación completa es irrealizable, proponiendo entender los programas de 
reparaciones masivas "como una contribución a la calidad de vida de los sobrevivientes" (De Greiff, 2011, p. 432). Sin embargo, como él mismo lo advierte, es necesario diferenciar entre los programas de desarrollo y los de reparación, toda vez que en el primer caso se trata de "programas que distribuyen bienes a los que tienen derecho [sus beneficiarios] como ciudadanos y no necesariamente como víctimas" (De Greiff, 2011, p. 439). ${ }^{14}$

Los mismos principios sobre reparación definen a quién debe considerársele víctima. No obstante, no puede pasarse por alto que, en la práctica, el reconocimiento de las víctimas implica decisiones y trámites administrativos más allá de dicha definición, sin que ello obste para que tal decisión sea fundamentada, en procura de asegurar un trato equitativo a los reclamantes.

De acuerdo con lo anterior, los programas de reparaciones masivas que se propone analizar son aquellos dirigidos a compensar a las víctimas, que atiendan los principios internacionales sobre la reparación como mandatos de optimización, de forma tal que guíen la actuación del Estado en la medida de lo posible (Alexy, 1993). De lo contrario, se estaría castigando doblemente a sociedades que han estado sometidas a abusos masivos al desconocer su derecho a tener una reparación completa.

Para estudiar estos programas, se propone indagar por su estabilidad y respaldo institucional, la publicidad de su diseño e implementación, la objetividad y publicidad en la definición y delimitación de la condición de víctima, las facilidades que se otorguen a los reclamantes para acceder a los programas, entre ellas la difusión de requisitos para tal efecto, y el alcance de las reparaciones.

La estabilidad y respaldo institucional dependerán de sus garantías de continuidad. En este sentido, es de esperar que si provienen del órgano legislativo su continuidad será mayor que si han sido creados por el ejecutivo y entonces están sujetos a que el gobierno de turno quiera implementarlos. En cuanto a publicidad de su diseño e implementación, debe considerarse la coordinación entre sociedad civil, víctimas y Estado. Respecto a objetividad 
y publicidad en materia del reconocimiento de la condición de víctima, y la difusión de requisitos para acceder a los programas, deberá considerarse si se establecen reglas suficientemente claras, canales efectivos de trasmisión de información y si dicha información es fácilmente comprensible y accesible para ciudadanos con diversidad étnica. Finalmente, para examinar el alcance de los programas de reparación, se propone considerar el tipo de beneficios ofrecidos y el número de beneficiarios. Ya que son programas masivos, deberán encaminarse a beneficiar, al menos, a un porcentaje significativo de víctimas.

\section{ii. Reparaciones simbólicas y judiciales}

Además de reparaciones materiales, se deben examinar las medidas simbólicas de reparación, que buscan reconocer el sufrimiento al que han sido sometidas las víctimas y que afecta a la sociedad en su conjunto (Gómez Isa, 2006). Para ello, se propone indagar si se han adelantado políticas de memoria; si, de forma aislada, se han declarado fechas conmemorativas o levantado monumentos en homenaje a las víctimas y cuál ha sido la difusión de dichas políticas o medidas aisladas. Finalmente, se propone analizar el nivel de cumplimiento, por parte de los estados, de las condenas judiciales tendientes a reparar, emitidas a nivel doméstico e internacional.

\section{Conclusiones}

Este trabajo buscó desarrollar un marco analítico para facilitar la comparación minuciosa e integral de los diferentes mecanismos de justicia transicional y sus trayectorias, en aras de contribuir al desarrollo de aquellos estudios que indagan no solo por las decisiones adoptadas en momentos transicionales, sino también por su evolución, ya sea porque los acuerdos iniciales han sido desafiados o, por el contrario, profundizados a través del tiempo.

Los mecanismos de justicia transicional no solo han sido aplicados en la gran mayoría de los países de América Latina, sino que se continúan aplicando décadas después de las transiciones. Esta es, pues, una región innovadora que sirve de ejemplo al resto del mundo y así lo refleja el desarrollo de su literatura sobre el tema. No 
obstante, falta llevar a cabo esfuerzos comparativos sistemáticos, y para ello es necesario la utilización de un marco analítico común.

Tomando como base el conjunto de principios actualizado para la protección y la promoción de los derechos humanos mediante la lucha contra la impunidad, así como los principios sobre el derecho de las víctimas a interponer recursos y obtener reparaciones, se formula una matriz que busca indagar por la garantía de los derechos a la verdad, la justicia y la reparación, a través del análisis de los mecanismos de justicia transicional. La aplicación sucesiva de dicha matriz, o criterios de análisis, da como resultado la trayectoria de los mecanismos de justicia transicional al evidenciar los cambios que a través del tiempo se presentan en estas materias.

No puede perderse de vista que el objetivo primario de los mecanismos de justicia transicional, cuyo análisis se propone, es garantizar los derechos de las víctimas. Después, hay otros efectos que se esperan, como evitar la repetición de las atrocidades y ayudar a la reconciliación; pero un paso anterior a examinar el impacto de su aplicación, en temas como la calidad de la democracia y en el respeto de los derechos humanos, está dado por el análisis de su efectividad para alcanzar su fin más básico, esto es, los derechos de las víctimas a la verdad, la justicia y la reparación.

Si bien el marco de análisis propuesto no tiene pretensiones explicativas, sino meramente descriptivas, no es menos cierto que el análisis integral de los mecanismos de justicia transicional y sus trayectorias es absolutamente necesario para la posterior exploración de factores determinantes de dichas trayectorias, puesto que para comparar apropiadamente es necesario partir de una misma base.

Se trata entonces de una guía de análisis que busca, de lo forma más minuciosa posible, contribuir al estudio empírico de un campo por naturaleza multidisciplinar, en el que confluyen politólogos, abogados, internacionalistas y estudiosos de los derechos humanos, entre otros, y que persiguen un diálogo entre saberes que vaya más allá de la consideración o cuantificación de la existencia de comisiones de la verdad, búsquedas, juicios y programas de reparaciones, para preguntarse por su alcance y contenido a través del tiempo. 


\section{Referencias}

Abrão, P. y Torelly, M. (2011). The reparations program as the lynchpin of transitional justice in Brazil. En F. Reátegui (ed.), Transitional Justice: Handbook for Latin America (pp. 407-440). Brasilia: Comisión Brasilera de Amnistía, Ministerio de Justicia.

Abrão, P. y Torelly, M. (2012). Resistance to Change: Brazil's persistent amnesty and its alternatives for Truth and Justice. En F. Lessa, y L. Payne (eds.), Amnesty in the Age of Human Rights Accountability (pp. 152.181). New York: Cambridge University Press.

ACNUDH. (2006). Estudio sobre el Derecho a la Verdad. En: Comisión Colombiana de Juristas, Principios internacionales sobre impunidad y reparaciones. Compilación de documentos de la Organización de las Naciones Unidas (ONU) (pp. 187-210). Bogotá: Opciones Gráficas Editores Ltda.

Alexy, R. (1993). Teoría de los derechos fundamentales. Madrid: Centro de Estudios Constitucionales.

Bernardi, B. (2013). O sistema interamericano de direitos humanos e a lei de justiça e paz na Colômbia: política doméstica e influência de normas internacionais. Contexto Internacional, 35, 139-172.

Bernardi, B. (2015a). O sistema interamericano de direitos humanos e a justiça de transição no Peru. Revista de Sociologia e Política, 23(54), 43-68.

Bernardi, B. (2015b). O sistema interamericano e a justiça de transição no México. Lua Nova, 94, 143-181.

Burt, J.-M. (2009). Guilty as charged: the trial of former President Alberto Fujimori for human rights violations. International Journal of Transitional Justice, 3(3), 384-405.

Burt, J.-M. (2012). Accountability after atrocity in Peru: the trial of former President Alberto Fujimori in comparative perspective. En N. Palmer, P. Clark, y D. Granville (eds.) Critical Perspectives in Transitional Justice (pp. 119-146). Cambridge: Intersentia Publishing Ltd.

Comisión Colombiana de Juristas (2007). Principios internacionales sobre impunidad y reparaciones. Compilación de documentos de la Organización de las Naciones Unidas (ONU). Bogotá: Opciones Gráficas Editores Ltda.

Collins, C. (2009). Human Rights Trials in Chile during and after the Pinochet Years. International Journal of Transitional Justice, 4(1), 67-86.

Collins, C., Balardini, L. y Burt, J.-M. (2013). Mapping Perpetrator Prosecutions in Latin America. International Journal of Transitional Justice, 7(1), 8-28.

Correa, C. (2011). Reparation programs for mass violations of human rights: lessons from experiences in Argentina, Chile and Perú. En F. Reátegui (ed.), Transitional Justice: handbook for Latin America (pp. 441476). Brasilia: Comisión Brasilera de Amnistía, Ministerio de Justicia. 
De Greiff, P. (2011). Justicia y Reparaciones. En F. Reátegui (ed.), Justicia Transicional. Manual para América Latina (pp. 407-440). Nueva York: Centro Internacional para la Justicia Transicional.

Dutrénit, S. (2012). Sentencias de la Corte Interamericana de Derechos Humanos y reacciones estatales (México y Uruguay ante los delitos del pasado). América Latina Hoy, 61, 79-99.

Fletcher, L. E., Weinstein, H. M. y Rowen, J. (2009). Context, Timing and the Dynamics of Transitional Justice: A Historical Perspective. Human Rights Quarterly, 31, 163-220.

Gómez Isa, F. (dir.) (2006). El derecho a la memoria. Zarautz: Instituto de Derechos Humanos Pedro Arrupe - Diputación de Guipuzcoa, Alberdania.

Gutiérrez, M. (2015a). Justicia en tiempos de transición: y después también. Revista Jurídicas, 12(1), 9-24.

Gutiérrez, M. (2015b). Justicia Pos-Transicional en Guatemala: el rol de los jueces en la protección de derechos humanos. Revista de Ciencia Política, 35(2), 347-370.

Hayner, P. (2001). Unspeakable Truths. Confronting state terror and atrocity. New York: Routledge.

Hayner, P. (2011). Unspeakable Truths. Transitional Justice and the Challenge of Truth Commissions. New York: Routledge.

Huneeus, A. (2011). Courts Resisting Courts: Lessons from the InterAmerican Court's Struggle to Enforce Human Rights. Cornell International Law Journal, 44(493), 493-533.

Kritz, N. (ed.) (1995). Transitional Justice: How Emerging Democracies Reckon with Former Regimes. Washington, USA: United States Institute of Peace.

Laplante, L. (2009). Outlawing Amnesty: The Return of Criminal Justice in Transitional Justice Schemes. Virginia Journal of International Law, 49, 8-26.

Martínez Barahona, E., Gutiérrez Salazar, M. L. y Rincón Fonseca, L. (2012). De la Locura a la Esperanza: ¿Nunca Más? Impunity in El Salvador and Guatemala. América Latina Hoy, 61, 101-136.

McAdams, J. (ed.) (1997). Transitional Justice and the Rule of Law in New Democracies. Notre Dame, IN: University of Notre Dame Press.

Méndez, J. E. (2011) Responsabilización por los abusos del pasado. En F. Reátegui (ed.), Justicia Transicional. Manual para América Latina (pp. 195-225). Nueva York: Centro Internacional para la Justicia Transicional.

Organización de las Naciones Unidas (ONU). (2004). Informe del Secretario General. El Estado de derecho y la justicia de transición en las sociedades que sufren o han sufrido conflictos. S/2004/616. Recuperado de http://www. un.org/es/comun/docs/?symbol=S/2004/616. 
Organización de las Naciones Unidas (ONU). (2005). Conjunto de Principios Actualizado para la Protección y la Promoción de los Derechos Humanos mediante la luch a contra la impunidad. Comisión de Derechos Humanos de la Organización de las Naciones Unidas. E/CN.4/2005/102/Add.1, 8 de febrero de 2005, aprobado mediante resolución No. 2005/81. En Comisión Colombiana de Juristas, 2007 (pp. 33-61). Bogotá: Opciones Gráficas Editores Ltda.

O’Donnell, G. y Schmitter, P. (1986). Transiciones desde un gobierno autoritario. Conclusiones tentativas sobre las democracias inciertas. Buenos Aires, Argentina: Paidós.

Olsen, T., Payne, L. y Reiter, A. (2010). Transitional Justice in Balance: comparing processes, weighing efficacy. Washington D. C.: United States Institute of Peace Press.

Payne, L., Abrão, P., y Torelly, M. (eds) (2011). A Anistia na Era da Responsabilização: O Brasil em Perspectiva Internacional e Comparada. Oxford: Oxford University, Latin American Centre.

Popkin, M. y Nehal, B. (1999). Latin American Amnesties in Comparative Perspective: Can the Past be Buried? Ethics and International Affairs, 13, 99-122.

Popkin, M., y Roht-Arriaza, N. (1995). Truth as Justice: Investigatory Commissions in Latin America. Law and Social Inquiry, 20(1), 79-116.

Reátegui, F. (ed.) (2011). Justicia Transicional. Manual para América Latina. Nueva York: Centro Internacional para la Justicia Transicional.

Salazar, K., y Antkowiak, T. (2007). Victims Unsilenced: The Inter-American Human Rights System and Transitional Justice in Latin America. Washington, D. C.: Due Process of Law Foundation.

Sandoval, C. (2008). The Challenge of Impunity in Peru: The Significance of the Inter-American Court of Human Rights. University of Essex Research Repository, 5(1), 1-20.

Sikkink, K., y Booth Walling, C. (2007). The Justice Cascade and the Impact of Human Rights Trials in Latin America. Journal of Peace Research, 44(4), 427-445.

Skaar, E. (2011). Judicial Independence and Human Rights in Latin America: Violations, Politics, and Prosecution. New York: Palgrave Macmillan.

Skaar, E., García-Godos, J. y Collins, C. (eds.) (2016). Transitional Justice in Latin America. The Uneven Road from Impunity towards Accountability. New York: Routledge.

Smulovitz, C. (2012). The past is never dead: accountability and justice for past human rights violations in Argentina. En M. Serrano, y V. Popovsky (eds.), After Oppression. Transitional Justice in Latin America and Eastern Europe (pp. 64-85). Tokio: United Nations University Press. 
Uprimny, R. y Lasso, L. M. (2004). Verdad, reparación y justicia en Colombia. En J. E. Borda Medina (ed.), Conflicto y seguridad democrática en Colombia. Temas críticos y propuestas. Bogotá: Fescol, Fundación Social.

Valencia Villa, H (2010). Justicia Transicional y Acuerdos de paz: hacia una "Lex Pacificatoria”. En C. Faleh Pérez, y C. Villán Duran (dirs.), Estudios sobre el derecho humano a la paz (pp.155-166). Madrid: Los Libros de la Catarata.

Van Zyl, P. (2011). Promoviendo la justicia transicional en sociedades posconflicto. En F. Reátegui (ed.), Justicia Transicional. Manual para América Latina (pp. 47-72). Nueva York: Centro Internacional para la Justicia Transicional.

Zalaquett, J. (1992). The Mathew O. Tobriner Memorial Lecture. Balancing Ethical Imperatives and Political Constraints. The Dilemma of New Democracies Confronting Past Human Rights Violations. Hastings Law Journal, 43(6), 1425-1438. 